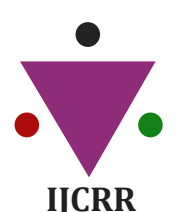

IJCRR

Section: Healthcare

Sci. Journal Impact

Factor: 6.1 (2018)

ICV: 90.90 (2018)

(c) (i) (5)

Copyright@IJCRR

\section{Correlation of Body Mass Index with Lipid Profile and Estradiol in Postmenopausal Women with Type 2 Diabetes Mellitus}

\author{
Priya Alva ${ }^{1}$, Aditi Bhandary ${ }^{2}$, Prajna Bhandary ${ }^{3}$, Pravesh Hegde ${ }^{4}$, \\ Neevan D' Souza ${ }^{5}$, Suchetha Kumari'
}

'Research Scholar, Nitte (Deemed to be University), Mangalore, India; ${ }^{A}$ Assistant Professor, Department of Medicine, Nitte (Deemed to be University), Mangalore, India; ${ }^{3 R e s e a r c h ~ A s s i s t a n t, ~ N i t t e ~(D e e m e d ~ t o ~ b e ~ U n i v e r s i t y), ~ M a n g a l o r e, ~ I n d i a ; ~}{ }^{4}$ Research Scholar, Nitte (Deemed to be University), Mangalore, India; ${ }^{5}$ Department of Statistics, Nitte (Deemed to be University), Mangalore, India; ${ }^{5}$ Professor, Department of BioChemistry, Nitte (Deemed to be University), Mangalore, India.

\title{
ABSTRACT
}

Introduction: The menopausal transition is a vulnerable period for developing obesity that predicts the future incident of developing type 2 diabetes mellitus (T2DM) and cardiovascular disease. Metabolism of lipid in diabetes is affected by insulin resistance and its deficiency.

Objective: To find the correlation of body mass index with lipid profile and Estradiol in postmenopausal women with type 2 diabetes mellitus by examining the level of lipid profile and Estradiol based on BMI.

Methods: A total of 120 postmenopausal females with type 2 Diabetes Mellitus were enrolled in the study. Venous blood was taken and analysed for total cholesterol, triglycerides, HDL-C, LDL-C, fasting glucose and estradiol. The height and weight of each patient were recorded. BMI was calculated and was categorized as normal, $(<18.5-24.9 \mathrm{~kg} / \mathrm{m} 2)$ overweight $(25-25 \mathrm{~kg} / \mathrm{m} 2)$, and obese $(<30)$.

Results: Among the lipid parameters, significantly raised the level of TG $139+31(p<0.04)$ and low levels of HDL $31+2.9$, ( $p<$ 0.03 ) were observed in the obese postmenopausal female when compared with the normal and overweight individual. A significantly higher Estradiol level was found in obese diabetic women $(p<.0 .05)$. A strong positive correlation was observed between Estradiol and TG with BMI and was negatively correlated with HDL-C.

Conclusion: Obese post-menopausal with diabetes exhibit high atherogenic risk profile and raised concentration of Estradiol.

Key Words: BMI, Estradiol, Obesity, Type 2 diabetes, Post-menopausal

\section{INTRODUCTION}

Diabetes mellitus is a global leading health concern among human society associated with a higher risk of mortality and morbidity. Cardiovascular disease is known to be one of the prime sources of demise among people with diabetes because lipid metabolism in diabetes is affected both by insulin resistance and insulin deficiency resulting in dyspilidemia. ${ }^{1}$ Diabetic dyslipidemia is marked by elevated triglycerides, low-density lipoprotein, and low high-density lipoprotein. The increasing prevalence of type 2 diabetes mellitus corresponds to an increasing rate of obesity. ${ }^{2}$ According to the world health organization, obesity is defined as body mass index $>30 \mathrm{~kg} / \mathrm{m}^{2} .{ }^{3}$ Compared to the lean individual, epidemi- ological studies report that obese women $(\mathrm{BMI}<30 \mathrm{Kg} / \mathrm{m} 2)$ shows the increase in the probability of developing diabetes. ${ }^{4}$ Lack of physical activity, higher dietary intake, decreased estrogen concentration result to alter insulin sensitivity in postmenopausal women. ${ }^{5}$ Previous studies have reported the strong relationship between increasing BMI, raised total cholesterol (TC), triglycerides (TG) and an inverse relationship with HDL-C ${ }^{6,7}$ without considering the estradiol level.

To our knowledge, the study which involved only postmenopausal women with a known history of type 2 diabetes mellitus is very rare. Therefore, we sought to evaluate the correlation between BMI with lipid profile and Estradiol in postmenopausal women with type 2 diabetes mellitus

\section{Corresponding Author:}

Dr. Suchetha Kumari N, Professor, Department of Bio-Chemistry, K.S.Hegde Medical Academy, Nitte (Deemed to be University), Mangalore, India; Email: Pri2720@gmail.com

ISSN: 2231-2196 (Print)

Received: 28.07 .2020
ISSN: 0975-5241 (Online)

Revised: 03.10 .2020
Accepted: 12.11 .2020
Published: 05.01.2021 


\section{MATERIALD AND METHODS}

A total of 130diabetic postmenopausal women between the age group of 45-65 years were enrolled from the tertiary care hospital in Mangalore from May 2019 to January 2020. Subjects with Pregnancy, chronic infection, renal disease were excluded from the study. After obtaining consent from each participants blood samples were collected. Study protocolwas approved by the institutional ethical committee (ISC/ KSHEMA/05/2017-18) of NITTE Deemed to be University.

Blood samples were obtained from each subject after overnight fasting via fluoride and plain tubes to analyze blood glucose and lipid profile respectively. Blood glucose was obtained from hospital records. Lipid parameters were analyzed using a semi-automated biochemistry enzymatic analyzer (STAR PLUS). A semi-structured questionnaire was used to interview each patient that included age, menopausal status, the period of menopause, diabetic status, etc. The height and weight of each subject were recorded. BMI was evaluated as weight in kilograms per height in meters squared $\left(\mathrm{kg} / \mathrm{m}^{2}\right)$. A BMI of $<18.5-24.9 \mathrm{~kg} / \mathrm{m}^{2}$ was considered as normal, $25-29.9$ $\mathrm{kg} / \mathrm{m}^{2}$ as overweight and $>30 \mathrm{~kg} / \mathrm{m}^{2}$ obesity $^{8}$. Hypercholesterolemia was defined as TC $>200 \mathrm{mg} / \mathrm{dl}$, high LDL-C $>130$ $\mathrm{mg} / \mathrm{dl}$, hypertriglyceridemia $\mathrm{TG}>150 \mathrm{mg} / \mathrm{dl}$ and HDL-C $>$ $40 \mathrm{mg} / \mathrm{dl}$. Total cholesterol, Triglyceride, LDL-C HDL-C $<200 \mathrm{mg} / \mathrm{dl},<150 \mathrm{mg} / \mathrm{dl},<130 \mathrm{mg} / \mathrm{dl}, \geq 40 \mathrm{mg} / \mathrm{dl}$ respectively were considered normal ${ }^{9}$ according to the third report of the national cholesterol education programme.

\section{Statistical Analysis}

SPPSS Version 16 was used for the analysis of obtained data. Parametric data were expressed as mean \pm standard deviation. The non-parametric test was expressed in the median and interquartile range. One way ANOVA was used to compare the lipid parameters between the groups. Pearson's and Spearman's correlation was calculated to correlate BMI with estradiol and lipid profile respectively. P-value $<0.05$ was considered significant.

\section{RESULTS}

A total of 130 postmenopausal diabetic women were included in our study. Mean age of the study population was 57.6 \pm 5.9. Mean fasting sugar was $159 \pm 61.5$. Patients were divided into three groups based on their BMI. Group 1 consists of a patient with normal BMI $\left(18.5-24.9 \mathrm{~kg} / \mathrm{m}^{2}\right)$, group 2 consists of a patient with overweight BMI values $\left(25-25 \mathrm{~kg} / \mathrm{m}^{2}\right)$, and group three were considered obese with the BMI $(\leq 30)$. Group 3 was noted to have higher TC $(178 \pm 45.0)$,LDL-C $(120 \pm 44.9)$ (Table 1).However, the difference was not statistically significant. Group 2 and 3 showed significantly higher TG $(p<0.048)$ when compared with the normal group. It was found that mean HDL-C was higher among normal BMI diabetic postmenopausal women. This difference across the BMI groups was statistically significant $(\mathrm{p}=0.031)$. estradiol concentration was higher among obese postmenopausal women

Table 1: Comparison of FBS, lipid parameters and estradiol levels with BMI among diabetic postmenopausal women.

\begin{tabular}{lllll} 
& $\begin{array}{l}\text { Normal } \\
\text { weight } \\
\mathbf{n}=43\end{array}$ & $\begin{array}{l}\text { Over } \\
\text { weight } \\
\mathbf{n = 4 0}\end{array}$ & $\begin{array}{l}\text { Obese } \\
\mathbf{n = 3 7}\end{array}$ & p-value \\
BMI & $\mathbf{2 2 . 2 + 2 . 4 4}$ & $\mathbf{2 7 . 4 + 1 . 3}$ & $34.0+2.4$ & 0.143 \\
FBS (mg/dl) & $148+30$ & $152+32.7$ & $160+36.1$ & $0.002^{*}$ \\
TC (mg/dl) & $169+46.0$ & $177+51.0$ & $178+45.0$ & 0.52 \\
TG (mg/dl) & $133+21.1$ & $140+27.5$ & $139+31.6$ & $0.048^{*}$ \\
HDL mg/dl) & $42.8+6.39$ & $37.1+4.9$ & $31+2.9$ & $0.031^{*}$ \\
LDL (mg/dl) & $103+45.1$ & $109+42.6$ & $120+44.9$ & 0.073 \\
VLDL (mg/ & $26.9+5.9$ & $27.7+8.1$ & $29.1+11.4$ & 0.123 \\
dl) & & & & \\
Estradiol & $0.3(0.1-0.4)$ & $1.16(0.4-$ & $1.3(1.0-$ & $0.042^{*}$ \\
(nmol/l) & & $1.65)$ & $2.1)$ & \\
\hline
\end{tabular}

Group 1-Normal BMI; Group 2: overweight BMI; Group 3: obese BMI.

Pearsons Co-efficient between BMI and lipid parameters showed negative correlation with HDL-C (r: - 0.144, p $\left.: 0.03^{*}\right)$ and positive correlation with TG(r: 0.028 , p:0.05) which was statistically significant (table 2 ). While there were no significant correlation with TC (r: -0.069 , p: 0.51$)$, LDLC (r: -0.028, p: 0.792), LDL-C/HDL-C (r: 0.139, p: 0.185), TC/ HDL-C RATIO(r :0.157, p:0.134) between BMI. (Data not shown).Asignificant positive correlation was observed between estradiol and BMI among post- menopausal diabetic women (0.231, $\mathrm{p}=0.02)$, Table: 3 .

Table 2: Pearson Correlation analysis between BMI and lipid parameters

\begin{tabular}{lcccc} 
mg /dl & BMI & TC & TG & HDL-C \\
TC & r: -0.069 & & & \\
& p: 0.51 & & & \\
TG & r: $: 0.028$ & r: 0.242 & & \\
& p: $0.05^{*}$ & p: 0.05 & & \\
HDL-C & r: 0.144 & r: $: 0.325$ & r: 0.061 & \\
& $p: 0.03^{*}$ & p: $0.05^{*}$ & p: 0.56 & \\
LDL-C & r: 0.131 & $r: 0.870$ & r: 0.098 & r: $: 0.560$ \\
& p: 0.21 & p: $0.000^{* *}$ & p: $: 350$ & p: $0.032^{*}$ \\
\hline
\end{tabular}

BMI: body mass index; TC: Total cholesterol; TG: Triglycerides; HDL-C: High-Density Lipoprotein;

LDL-C: Low-Density Lipoprotein. * Correlation considered significant when $\mathrm{p}<0.05{ }^{*}$ Correlation considered highly significant when $\mathrm{p}<0.01$. 
Table 3: Spearman's correlation between estradiol with BMI, lipid Parameters

\begin{tabular}{|c|c|c|c|c|c|}
\hline & BMI & TC & TG & HDL-C & LDL-C \\
\hline $\begin{array}{l}\text { Estradiol } \\
(\mathrm{nmol} / \mathrm{l})\end{array}$ & $\begin{array}{l}0.231^{*} \\
(0.02)\end{array}$ & $\begin{array}{l}-0.072 \\
(0.79)\end{array}$ & $\begin{array}{l}0.139 \\
(0.18)\end{array}$ & $\begin{array}{l}0.280 \\
(0.13)\end{array}$ & $\begin{array}{l}0.058 \\
(0.58)\end{array}$ \\
\hline
\end{tabular}

BMI: body mass index; TC: Total cholesterol; TG: Triglycerides; HDL-C: High-Density Lipoprotein;

LDL-C: Low-Density Lipoprotein. *Correlation considered significant when $\mathrm{p}<0.05$

\section{DISCUSSION}

Previous data report that the key determinant factor of metabolic disorders like CVD, diabetes, dyslipidaemia, hypertension, hyperinsulinemia depends upon the relationship between body fat and lipid profile. ${ }^{10,11}$ The present study evaluates the correlation of BMI with lipid profile and serum estradiol in postmenopausal women with diabetes.

Our study reported an equivalent correlation between serum Triglycerides and BMI, with a raised concentration of triglycerides observed in overweight and obese person. This is per the previous study which showed an association between BMI and triglycerides. ${ }^{12}$ HDL $-\mathrm{C}$ was found to be lower in obese population when compared with normal and overweight. As BMI increases due to an increase in adiposity, the prevalence of disease associated with insulin resistance increases characterized by decreased HDL-C and increased triglycerides. A study conducted in Nigeria also reported a negative correlation of HDL-C with BMI ${ }^{13}$. Likewise similar to our study another study by Shamai.et.al also reported an association between BMI, HDL-C, and TG ${ }^{14}$ Raised level of triglyceride concentration occurs due to the high production of VLDL and reduced clearance of it thereby resulting in depletion of cholesterol esters in HDL to cholesterol ester enrichment in triacylglycerol rich lipoprotein..$^{15}$ One more study by Biadgo .et.al explains that in diabetes increased secretion of LDL-C by the liver causes the slow level of removal of TG with the increased level of substrate required for TG production. ${ }^{16}$

Obesity and overweight have been an increasing public health concern in postmenopausal women ${ }^{16,17}$. A BMI $>25$ $\mathrm{Kg} / \mathrm{m}^{2}$ is related with increased morbidity, essentially from $\mathrm{DM}$ and $\mathrm{CVD}$, whereas a BMI $>30 \mathrm{Kg} / \mathrm{m}^{2}$ is related with the expanded chance for both morbidity and mortality, the lastmentioned basically from diabetes, coronary heart disease (CHD), and stroke. ${ }^{18}$ In the present study raised level of estradiol was observed in the obese population when compared with the other two groups. Obtained data was consistent with another study that reports, thin post-menopausal women have lower estrogen levels than do obese women. ${ }^{19}$ Moreover, estradiol was positively correlated with BMI. The positive association of the present study is consistent with those from previous studies. ${ }^{20,21}$ Approximately $83 \%$ and $60 \%$ of higher levels of estradiol and estrone respectively were estimated in obese postmenopausal women (BMI> $30 \mathrm{~kg} / \mathrm{m}$ ) in a pooled analysis of eight studies. ${ }^{22}$ The mechanism that supports the higher level of estrogen may be due to the aromatization of androgens in adipose tissue..$^{23,24}$

\section{CONCLUSION}

From the Present study, it can be concluded that postmenopausal women with diabetes mellitus exhibit high atherogenic risk profile due to their abnormal BMI, higher TG, estrogen, and lower HDL-C. The impact of BMI on lipid profile in diabetic patient is a key factor for the development of atherosclerosis and CVD. Poor glycemic control and sedentary lifestyle may be a sole factor for this outcome. Therefore, educating T2DM patients about glycemic control through diet and exercise is a basic necessity. Thus, the progression of the disease can be delayed. Dyslipidaemia in T2DM postmenopausal women can be improved with normal BMI and low estrogen concentration. Further studies with larger sample size are needed to identify the exact cause of obesity that influences lipid profile in diabetes.

\section{ACKNOWLEDGMENT}

We express deep gratitude to all the participants for their excellent support. Authors acknowledge the great help received from the scholars whose articles cited and included in reference to this manuscript. The authors are also grateful to authors/editors / publishers of all those articles, journals and books from where the literature for this article has been reviewed and discussed.

\section{Source of Funding: Nitte (Deemed to be University)}

\section{Conflict of Interest: Nil.}

\section{REFERENCES}

1. Gordon L, Ragoobirsingh D, St Errol YA, Choo-Kang E, McGrowder D, Martorell E. Lipid profile of type 2 diabetic and hypertensive patients in the Jamaican population. J Lab Phys 2010; 2(1):25.

2. Zimmet P, Alberti KG, Shaw J. Global and societal implications of the diabetes epidemic. Nature 2001 Dec;414(6865):782-7.

3. Heslehurst N, Sattar N, Rajasingam D, Wilkinson J, Summerbell $\mathrm{CD}$, Rankin J. Existing maternal obesity guidelines may increase inequalities between ethnic groups: a national epidemiological study of 502,474 births in England. BMC Pregn Childbirth 2012 Dec 1;12(1):156.

4. Han TS, Sattar N, Lean M. Assessment of obesity and its clinical implications. BMJ 2006 Sep 28;333(7570):695-8.

5. Priya P, Lathif F, Raghavan V. Correlation Between Body Mass Index (BMI) and Fasting Glucose in Post-menopausal Women. Nur J Ind 2017 May 1;108(3):103. 
6. Krauss RM, Winston M, Fletcher BJ, Grundy SM. Obesity: impact on cardiovascular disease. Circulation 1998 Oct;98(14):1472-6.

7. Denke MA, Sempos CT, Grundy SM. Excess body weight: an under-recognized contributor to dyslipidemia in white American women. Arch Internal Med 1994;154(4):401-10.

8. Who EC. Appropriate body-mass index for Asian populations and its implications for policy and intervention strategies. Lancet 2004 Jan;363(9403):157.

9. Third report of the National Cholesterol Education Program (NCEP) expert panel on detection, evaluation, and treatment of high blood cholesterol in adults (adult treatment panel III). National Cholesterol Education Program, National Heart, Lung, and Blood Institute, National Institutes of Health; 2002.

10. Dixit AK, Dey R, Suresh A, Chaudhuri S, Panda AK, Mitra A, et al. The prevalence of dyslipidemia in patients with diabetes mellitus of Ayurveda Hospital. J Diab Metab Disor 2014 Dec;13(1):58.

11. Hussain A, Ali I, Ijaz M, Rahim A. Correlation between hemoglobinA1c and serum lipid profile in Afghani patients with type 2 diabetes: hemoglobin A1c prognosticates dyslipidemia. Therapeutic Adv Endoc Metab 2017;8(4):51-7.

12. Sandhu HS, Koley S, Sandhu KS. A study of the correlation between lipid profile and body mass index (BMI) in patients with diabetes mellitus. J Hum Ecol 2008;24(3):227-9.

13. Omotoye FE, Fadupin GT. Effect of body mass index on the lipid profile of type 2 Diabetic patients at an urban tertiary hospital in Nigeria. IOSR-JDMS. 2016 Sep;15(9):65-70.

14. Shamai L, Lurix E, Shen M, Novaro GM, Szomstein S, Rosenthal R, et al. Association of body mass index and lipid profiles: evaluation of a broad spectrum of body mass index patients including the morbidly obese. Obesity Surg 2011;21(1):42-7.

15. Arora M, Koley S, Gupta S, Sandhu JS. A study on lipid profile and body fat in patients with diabetes mellitus. Anthropologist 2007;9(4):295-8.
16. Bingo B, Abebe SM, Baynes HW, Yesuf M, Alemu A, Abebe M. Correlation between serum lipid profile with anthropometric and clinical variables in patients with type 2 diabetes mellitus. Ethi J health Sci 2017;27(3):215-26.

17. Awa WL, Fach E, Krakow D, Welp R, Kunder J, Voll A, et al. Type 2 diabetes from pediatric to geriatric age: analysis of gender and obesity among 120183 patients from the German/Austrian DPV database. Eur J Endocri 2012;167(2):245.

18. Hinge CR, Ingle SB, Adgaonkar BD. Body Mass Index, Blood Pressure and Lipid profile in type 2 diabetes-Review. Int J Cur Res Rev 2018;10(10):1.

19. Barton M. Obesity and aging: determinants of endothelial cell dysfunction and atherosclerosis. Pflügers Arch Eur J Phys 2010;460(5):

20. Judd HL, Davidson BJ, Frumar AM, Shamonki IM, Lagasse LD, Ballon SC. Serum androgens and estrogens in postmenopausal women with and without endometrial cancer. Ame J Obst and Gyne 1980;136(7):859-66.

21. Hankinson SE, Willett WC, Manson JE, Hunter DJ, Colditz GA, Stampfer MJ, et al. Alcohol, height, and adiposity in relation to estrogen and prolactin levels in postmenopausal women. J Nat Cancer Inst 1995;87(17):1297-302.

22. Mahabir S, Baer DJ, Johnson LL, Hartman TJ, Dorgan JF, Campbell WS, et al. The usefulness of body mass index as a sufficient adiposity measurement for sex hormone concentration associations in postmenopausal women. Cancer Epidemiol Prev Biomark 2006; 15(12):2502-7.

23. Endogenous Hormones Breast Cancer Collaborative Group. Body mass index, serum sex hormones, and breast cancer risk in postmenopausal women. J Nat Cancer Insti. 2003;95(16):121826.

24. Folkerd EJ, James VH. Aromatization of steroids in peripheral tissues. J Steroid Biochem 1983;19(1):687-90. 